\title{
Performance Evaluation of the Hot and Warm Stone Mastic Asphalt Mixture
}

\author{
Yu Wu ${ }^{1, a}$, Jing Wang ${ }^{2, b^{*}}$, Miao $\mathrm{Wu}^{3, \mathrm{c}}$, Jun $\mathrm{Lan}^{3, \mathrm{~d}}$ gen $\mathrm{Li}^{4, \mathrm{e}}$ \\ ${ }^{1}$ Henan Zhongyuan Highway Corporation Xindeng Branch, Zhengzhou,China,45000 \\ ${ }^{2}$ Beijing University of Architecture and Civil Engineering, TRC,Beijing, China, 100044 \\ ${ }^{3}$ Henan Zhuxin Highway Extension Engineering Ltd, Henan Xinyang, China,464000 \\ ${ }^{4}$ Beijing Municipal Road and Bridge Building Material Group Ltd, Beijing, China,100026 \\ awuyu@163.com ${ }^{\mathrm{b}}{ }^{*}$ wangjing2705@163.com, ${ }^{\mathrm{c}}$ xu-sf@126.com, ${ }^{\mathrm{d}} 18601227805 @ 163 . c o m$,
}

Keywords: Warm Mix Asphalt; Hot Mix Asphalt; LRT; SMA; Pavement performance; Evaluation and Comparison

Abstract. Warm Mix Asphalt is a new type of asphalt mixture which can reduces the mixing temperature and emissions. A kind of warm agent (LRT) is chosen in this study. Hot and warm mix asphalt mixture were designed and their high temperature, low temperature, moisture sensitivity and fatigue pavement performance were evaluated. the tests results is shown that HMA is slightly better in moisture resistance while WMA is slightly better in rutting and cold cracking resistance. About $30^{\circ} \mathrm{C}$ reduction in mixing temperature can be achieved by using LRT, which resulted in a significant reduction in fuel consumption and exhaust emission.

\section{Introduction}

Traditional HMA asphalt needs to be heated to $150^{\circ} \mathrm{C} \sim 180^{\circ} \mathrm{C}$, and aggregate needs to be heated to $170^{\circ} \mathrm{C} \sim 190^{\circ} \mathrm{C}$, heating up to such a high temperature need to consume a lot of energy, in the production and construction process will produce a lot of waste gas and dust, will cause serious environmental pollution[1].WMA is a kind of green environmental protection of asphalt mixture production technology, this technology was first developed in 1995 by Shell and Kolo-veidekke. Relative to traditional HMA, WMA production and compaction temperature will be reduced by about $30^{\circ} \mathrm{C}$, and mixture workability and road performance can be comparable with HMA, which not only reduces resource consumption but also reduces environmental pollution[2].

At present, there are many kinds of warm mix asphalt mixture, and the technology is mainly the following: Aspha-Min ${ }^{\circledR}$, WAM-Foam ${ }^{\circledR}$, Viscosity and Drag Reducer, based on Asphalt Emulsion, LEA, Sulphur Modified Asphalt. In this paper, WMA is achieved by adding a viscosity and drag reducer(LRT) in asphalt mixture. SMA-13 asphalt mixture was used to analyze the road performance of HMA and WMA[3,4].

\section{Performance of WMA}

The warm mix agent in this paper is called LRT which is a kind of viscous liquid. It can't dissolve in water but can dissolve in alcohol and aromatic hydrocarbon. The warm mix agent LRT is also a kind of surface active agent[5]. It can reduce the resistance during mixing between asphalt and aggregates. Thus, it can reduce the mixing and compaction temperature[6]. The content of LTR is so less that it could be only $0.2 \% \sim 0.5 \%$ weight of asphalt. It is easy to add in asphalt and can simplified production process and avoid equipment modification. Therefore, using of LTR can greatly facilitate the production of asphalt mixtures in factory. LRT has little influence on the physical and chemical properties of asphalt. The warm mix asphalt can be stably stored 7 days or more[7]. It greatly increases the flexibility and convenience. It can maintain the physical and mechanical properties the same as traditional hot mix asphalt well[8]. 
LTR can't easily dispersed in asphalt because of its viscous state. In order to ensure the full integration between LTR and SBS modified asphalt, SBS modified asphalt should be heated up to about $150^{\circ} \mathrm{C}$ and processed about 20min with high-speed cutting machine after LRT added.

Hot mix asphalt in this paper is SBS modified asphalt. Warm mix asphalt is prepared by adding warm mix agent. Some properties index is shown in Table 1.

Table 1Performance index of SBS modified asphalt

\begin{tabular}{ccccc}
\hline Test item & HMA & WMA & $\begin{array}{c}\text { Technical requirements } \\
\text { of modified asphalt }\end{array}$ & Method \\
Penetration $\left[25^{\circ} \mathrm{C}, 100 \mathrm{~g}, 5 \mathrm{~s}, 0.1 \mathrm{~mm}\right]$ & 60 & 61 & $30 \sim 60$ & T0604-2011 \\
Ductility $\left[5^{\circ} \mathrm{C}, \mathrm{cm}\right]$ & 40 & 39 & $\geq 30$ & T0605-2011 \\
Softening point $\left[{ }^{\circ} \mathrm{C}\right]$ & 80 & 85 & $\geq 55$ & $\mathrm{~T} 0606-2011$ \\
Brookfield Viscosity $\left[135^{\circ} \mathrm{C}, \mathrm{Pa} \cdot \mathrm{s}\right]$ & 2.18 & 1.03 & $\leq 3$ & $\mathrm{~T} 0625-2011$ \\
\hline
\end{tabular}

\section{Mix Design}

The raw materials of SMA asphalt mixture include coarse and fine aggregate, asphalt and fiber, and the performance indexes meet the requirements of the regulations. Related technical indicators of asphalt have been listed in the previous paper, Fiber selection of loose wood cellulose, its performance indexs are show in Table 2.

Table 2 Fiber performance index

\begin{tabular}{cccc}
\hline Index & Unit & Test results & Technical requirements \\
Ash content & $\%$ & 20.1 & $18 \pm 5$, No volatiles \\
PH & -- & 7.5 & $7.5 \pm 1.0$ \\
Oil absorption & $\%$ & 5.0 & $5.0 \pm 1.0$ times of fiber quality \\
Water content & $\%$ & 3.0 & $<5 \%$ ( quality) \\
\hline
\end{tabular}

In this paper, SMA-13 asphalt mixture was used to mix proportion design. Three kinds of gradation are chosen as the test grade, through the comparison of the performance, final, chosen the gradation 2 as the mix design. asphalt mixture ratio and gradation curve are shown in Fig. 1.

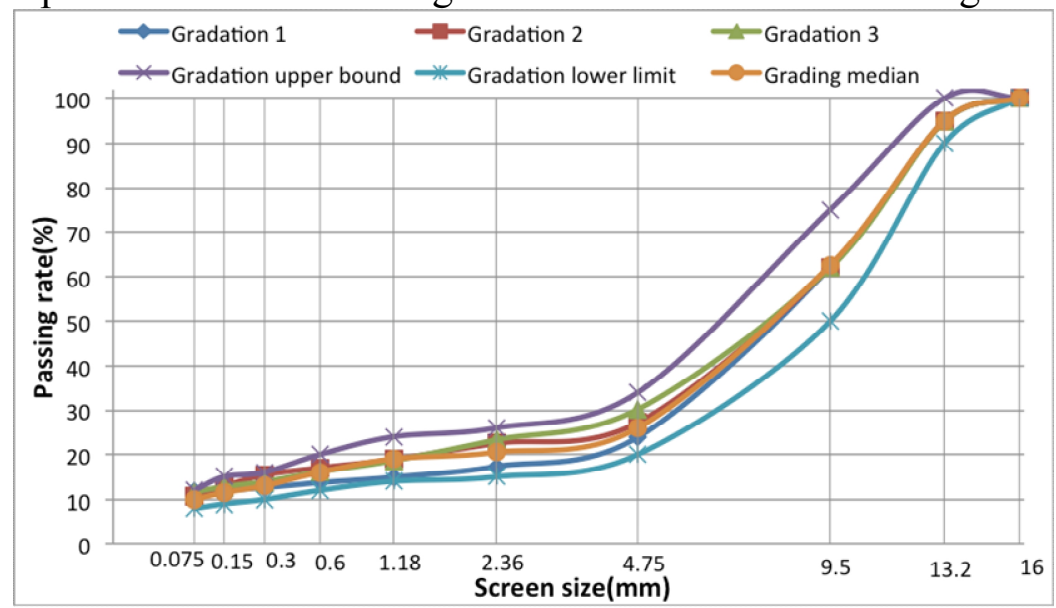

Fig. 1 Grading curve

In this paper, Marshall design method used to determine the optimum asphalt aggregate ratio, Asphalt dosage was determined to be $6.2 \%$.In this asphalt content, asphalt mixture void ratio is $4.1 \%$, the performance indexes meet the requirements of specification.

\section{Pavement Performance of HMA and WMA}

In this paper, the high temperature stability, water stability, low temperature crack resistance and fatigue performance of hot and warm SMA-13 asphalt mixture was compared and analyzed. 
High temperature stability. To detection the ability of rutting resistance performance of asphalt mixture, in this paper, we choose the method of $\mathrm{T}$ 0719-2011 to test the high temperature stability of asphalt mixture, the results are shown in 3.

Table 3 High temperature stability

\begin{tabular}{|c|c|c|c|c|}
\hline Type & Asphalt & Compaction temperature $\left[{ }^{\circ} \mathrm{C}\right]$ & $\mathrm{DS}[$ times $/ \mathrm{mm}]$ & Method \\
\hline $\begin{array}{c}\text { HMA } \\
\text { SMA-13 }\end{array}$ & SBS modified asphalt & 170 & 8630 & Т 0719-2011 \\
\hline $\begin{array}{c}\text { WMA } \\
\text { SMA-13 }\end{array}$ & warm asphalt & 140 & 9066 & Т 0719-2011 \\
\hline
\end{tabular}

Water stability. To detection the ability of water stability of asphalt mixture, in this paper, we choose the method of T 0709-2011 and T 0729-2000 to test the water stability of asphalt mixture, the results are shown in Table 4 and Table 5.

Table 4 Water immersion performance of Marshall

\begin{tabular}{|c|c|c|c|c|}
\hline Type & Asphalt & Compaction temperature $\left[{ }^{\circ} \mathrm{C}\right]$ & $\mathrm{MS}_{0}[\%]$ & Method \\
\hline $\begin{array}{c}\text { HMA } \\
\text { SMA-13 }\end{array}$ & SBS modified asphalt & 170 & 92.5 & T 0709-2011 \\
\hline $\begin{array}{c}\text { WMA } \\
\text { SMA-13 }\end{array}$ & warm asphalt & 140 & 85.4 & Т 0709-2011 \\
\hline \multicolumn{5}{|c|}{ Table 5 Performance of freezing and thawing } \\
\hline Type & Asphalt & Compaction temperature $\left[{ }^{\circ} \mathrm{C}\right]$ & TSR $[\%]$ & Method \\
\hline $\begin{array}{c}\text { HMA } \\
\text { SMA-13 }\end{array}$ & SBS modified asphalt & 170 & 91.8 & T 0729-2000 \\
\hline $\begin{array}{c}\text { WMA } \\
\text { SMA-13 }\end{array}$ & warm asphalt & 140 & 88.5 & T 0729-2000 \\
\hline
\end{tabular}

Low-temperature crack resistance. To evaluate low-temperature crack resistance, in this paper, we use the UTM-25 reference the test method of T0715-2011.

Test temperature: $-10^{\circ} \mathrm{C} \pm 0.5^{\circ} \mathrm{C}$; Loading Speed: $50 \mathrm{~mm} / \mathrm{min}$.

Molding Methods: Roller compactor and cut beams. Size: $30 \mathrm{~mm} * 35 \mathrm{~mm} * 250 \mathrm{~mm}$. Put test specimen in the cryostat to $-10^{\circ} \mathrm{C}$ over $3 \mathrm{~h}$ before test. The results are shown in Table 6 .

Table 6 Low-temperature crack resistance

\begin{tabular}{|c|c|c|c|c|}
\hline Type & Asphalt & Compaction temperature $\left[{ }^{\circ} \mathrm{C}\right]$ & Failure strain[\%] & Method \\
\hline $\begin{array}{c}\text { HMA } \\
\text { SMA-13 }\end{array}$ & $\begin{array}{l}\text { SBS modified } \\
\text { asphalt }\end{array}$ & 170 & 2878 & Т 0715-2011 \\
\hline $\begin{array}{c}\text { WMA } \\
\text { SMA-13 }\end{array}$ & warm asphalt & 140 & 6157 & Т 0715-2011 \\
\hline
\end{tabular}

Fatigue performance. To evaluate fatigue performance, in this paper, we use the UTM-25 reference the test method of T0739-2011.

Control modes: stress control ; Temperature: $15 \pm 1^{\circ} \mathrm{C}$; Loading wave: Continuous haversine loading 10Hz; Stress ratio:0.4、0.5、0.6、0.7.

Molding Methods: Shear compaction and cut beams. Size: $40 \mathrm{~mm} * 40 \mathrm{~mm} * 250 \mathrm{~mm}$. Test pieces of damage as the standard of fatigue damage. The results are shown in Table 7 
Table 7 Fatigue performance

\begin{tabular}{|c|c|c|c|c|}
\hline Type & $\begin{array}{l}\text { Failure load } \\
\qquad[\mathrm{KN}]\end{array}$ & $\begin{array}{l}\text { Bend strength } \\
{[\mathrm{MPa}]}\end{array}$ & $\begin{array}{c}\text { Stress ratio and average no. of } \\
\text { fatigue effects }[\%]\end{array}$ & $\begin{array}{l}\text { Fatigue equation and } \\
\text { correlation coefficient }\end{array}$ \\
\hline $\begin{array}{l}\text { HMA } \\
\text { SMA-13 }\end{array}$ & 1.44 & 6.75 & $\begin{array}{rrrr}0.4 & 0.5 & 0.6 & 0.7 \\
18760 & 4668 & 2480 & 1190\end{array}$ & $\begin{array}{c}\mathrm{y}=-3.87 \mathrm{x}+5.73 \\
\mathrm{R}^{2}=0.9648\end{array}$ \\
\hline $\begin{array}{l}\text { WMA } \\
\text { SMA-13 }\end{array}$ & 0.81 & 3.82 & $\begin{array}{rrrrr} & 0.4 & 0.5 & 0.6 & 0.7 \\
24517 & 14309 & 5322 & 3453\end{array}$ & $\begin{array}{c}y=-2.98 x+5.59 \\
R^{2}=0.9778\end{array}$ \\
\hline
\end{tabular}

Through the above performance indicators can be seen that water damage resistance of HMA is slightly better than WMA, but the high temperature stability and low temperature cracking resistance of WMA is slightly better than HMA, and the fatigue property of WMA is obviously higher than that HMA.

\section{Summary}

The conclusions are got the study of performance evaluation and comparison of hot and warm stone mastic asphalt in this paper as following:

(1) LTR as a surface action agent use in this study, it could reduce the temperature of asphalt mixture in mixing and compacting, by reducing asphalt and aggregate mixture resistance. The compaction temperature of WMA is $140^{\circ} \mathrm{C}$, about $30^{\circ} \mathrm{C}$ reduction comparison with $\mathrm{HMA}$, which resulted in a significant reduction in fuel consumption and exhaust emission;

(2) The performance indicators satisfy the need of Technical Requirement Manual of Hot Stone Mastic Asphalt Mixture;

(3) Comparison with HMA, WMA water stability is of relatively lower, rutting and cold cracking resistance is of relatively better, the fatigue performance is apparently higher.

\section{References}

[1] Matthew Corrigan. Warm Mix Asphalt Technology.AASHTO Standing Committee on Highways Technical Meeting, September 16, 2005

[2] Sun Daquan, Wang Xitong, Tang Shiliang, Chu Lihua, Luo Jie. Research Progress of Preparatio$\mathrm{n}$ technology for environment - friendly Warm Mix Asphalt[J], PETROLEUM ASPHALT, In Chinese, 2007.8, 21(4)

[3] LU Zhenglan, SUN Lijun, ZHOU Chaohui. Performance and mixture design of high quality asphalt modified by SEAM[J], ACTA PETROLEI SINICA(PETROLEUM PROCESSING

SECTION), In Chinese, 2005.10,21(5)

[4]Xu Shifa, Yan Bin, Ji Jie. Present situation and application prospect of high energy saving and low emission of WMA[J], Highway, 2005, In Chinese, (7): 195-198.

[5]Lu Weimin, Sun Daquan. Asphalt mixture design manual. BeiJing: China Communication Press, In Chinese,2007.5

[6]Technical Specification for Construction of Highway Asphalt Pavements (JTG F40-2004).

BeiJing: China Communication Press, In Chinese,2004.09

[7]Standard Test Methods of Bitumen and Bituminous Mixtures for Highway Engineering (JTG E20-2011), BeiJing: China Communication Press, In Chinese,2011.09

[8] Ji Jie, Wang Ruiying, Xu Shifa, Yan Bin. A comparative study on the performance of high energy saving low emission warm mix asphalt mixture and hot mix asphalt mixture[J]. Journal of Highway and Transportation Research and Development, In Chinese,2006(11):90-92. 